\title{
What Do Differences Between Own, Admired, and Attributed Choices Have To Do with Group Induced Shifts in Choice ${ }^{1}$
}

\author{
Eugene Burnstein and Amiram Vinokur \\ University of Michigan
}

AND

\author{
Marie-France Pichevin \\ Université de Provence
}

\begin{abstract}
Two studies examined certain discrepancies which have been considered important evidence in support of interpersonal comparison (value-adherence) explanations of group induced shifts in choice. These are (a) the differences between a person's own choice and the choice he predicts others would make and (b) the difference between the former and the choice he admires. Findings from the first study indicate that own choices are more extreme than those a person predicts others would make because he is more certain and confident about the former than the latter, not because he wishes to appear to outdo others as interpersonal comparison theories of choice-shift effect would have it. The second study strongly suggests that extreme choices are admired not because they display maximal adherence to a social ideal but because they imply that the person's solution to a problem involving choice is well-founded, that he has persuasive reasons for the choice. On the whole the evidence bodes well for explanations of choice-shift effects based on persuasive argumentation and poorly for those relying on interpersonal comparison processes.
\end{abstract}

Despite prolonged sermons (e.g., Moscovici \& Lecuyer, 1972) and brief laments (e.g., Smith, 1972) to the contrary, research on group induced revisions in individual choice-the ill-named "risky shift"- has in fact progressed to where critical experimentation seems possible. The issues at hand in this area have to do with the necessary and sufficient conditions

${ }^{1}$ This research was supported by a grant from the National Institute of Mental Health (MH 16950-05) and by a Guggenheim Foundation Fellowship awarded to the first author. We are grateful to colleagues at the Social Psychology Laboratory of the Université de Provence for making their facilities available to us.

428

Copyright (C) 1974 by Academic Press, Inc.

All rights of reproduction in any form reserved. 
for producing such shifts. There are two distinct theoretical views. One stresses interpersonal comparisons and the other, persuasive argumentation-reflecting the common distinction between normative and informational processes (Deutsch \& Gerard, 1955).

Interpersonal comparison theories also often referred to as value theories (Levinger \& Schneider, 1969; Jellison \& Riskind, 1970; Pruitt, $1971 \mathrm{~b})$, all argue that the shift is due to normative processes. For instance, according to Brown (1965), upon comparing himself with others and learning his choice is relatively moderate, a group member experiences some distressful emotions-fear of disapproval, loss in selfesteem, etc. This unfortunate state of affairs is said to come about because the member believes such moderation does not reflect adequate adherence to widely cherished social values. To avoid further discomfort, this individual abandons his initial choice for one he thinks will demonstrate proper adherence, a choice which will make him at least as extreme as most other members. A more detailed review of these approaches to the choice-shift effect appears in Cartwright (1971), Pruitt (1971a,b), and Vinokur (1971).

Persuasive-arguments theory (St. Jean, 1970; Vinokur, 1971; Vinokur \& Burnstein, 1974) attributes shifts in choice to informational processes which commonly occur during individual and group problem-solving. It assumes that a particular decision brings to mind a set of standard arguments in support of the various alternatives among which the person must choose. A member's initial choice is said to be due to the kind of persuasive arguments available to him. The shifts in choice following discussion are assumed to result from the sharing of arguments which were only partially available to the average member prior to discussion. A more thorough presentation of this approach can be found in Burnstein and Vinokur (1973) and in Vinokur and Burnstein (1974).

Two main research strategies have been used to examine interpersonal comparison and persuasive argumentation processes. One consists of experiments which try to determine if shifts in choice occur when either comparison processes or persuasive argumentation is prevented from occurring. Suffice to say that shifts are obtained following persuasive argumentation even when interpersonal comparison processes are minimized or precluded; they rarely occur, however, if interpersonal comparison can take place but persuasive argumentation is minimized or precluded (Burnstein \& Vinokur, 1973; Burnstein et al., 1973; Clark et al., 1971; St. Jean, 1970; Wallach \& Kogan, 1965). While a few studies have obtained shifts in choice under the latter conditions, in each case they have been rather attenuated ones (e.g., Clark \& Willems, 1969; Teger \& Pruitt, 1967). This research paradigm, therefore, provides con- 
siderable evidence against comparison theories and for persuasive argumentation.

The second strategy involves studies in which a person judges (a) how most others like him would choose or (b) what choice he admires. In general the former estimate tends to be less extreme, and the latter estimate, more extreme than the person's own choice. These discrepancies are taken as evidence that individuals wish to outstrip each other in their adherence to particular social values, a hypothesis which is central to theories of interpersonal comparison. For instance, according to Brown (1965) Western culture positively values risk in certain decisions (or caution in other decisions); as a sign of his own competence or worth the individual wants to believe he is at least as risky (or cautious) as most others (Jellison \& Riskind, 1970). This yearning to outshine in turn would lead to shifts in choice among relatively moderate individuals once they have had an opportunity to compare themselves with others.

The finding that admired choices tend to be more extreme than one's own choice is readily explained by the Levinger and Schneider (1969) or the Pruitt (1971b) version of interpersonal comparison theory, both of which assume that an individual's decision is the result of a compromise between group norms and abstract ideals or extreme exemplars. Also, Brown's formulation is vague enough to encompass the effect with no great strain. For instance, he might assert that actually choosing usually involves competing values (e.g., be bold but not foolhardy); while merely admiring is not so constrained. Thus, admiration is likely to be an unalloyed expression of the dominant value engaged by the decision (riskiness on decisions known to shift toward risk and cautiousness on those given to shifts toward caution).

There are, however, other findings involving these discrepancies which do not make a great deal of sense in terms of the value adherence hypothesis. For instance, in the original Levinger and Schneider (1969) study, the self-ideal discrepancy appears to be a rather unreliable guide on cautious items (but not on risky items). In addition, the order in which the judgments are made has powerful effects, the discrepancies being much reduced when the choice of others or the ideal choice is made before one's own choice (McCauley, Kogan, \& Teger, 1971; Myers, 1973a). On the other hand interpersonal comparison processes, according to these researchers, imply the reverse would occur. Being concerned about others' choices or about admirable choices before getting down to one's own preferences will make the value-adherence implications of the choice comparison (own vs others, or own vs admired) more salient than being unconcerned about these matters until after settling one's own 
preferences-especially since the person probably does not foresee that he will be asked immediately afterward to consider what others would choose or what choice he admires. Thus the discrepancy between own and others' or admired choices should be greater if the former is made after rather than before the latter, which is not at all what was found.

Finally, and most importantly, in their recent work Lamm, Trommsdorff, and Rost-Schaude (1972) find no relationship between the magnitude of the shifts and the self-other discrepancies, although a positive relationship should be obtained according to the value-adherence hypothesis. In spite of their previous research (Lamm, Schaude, \& Trommsdorff, 1971) these authors are now convinced that self-other discrepancies have no connection with the choice shift, a possibility also suggested by Cartwright in his review (1971). According to the latter author, self-other discrepancies and choice shifts may well be causally unrelated, as the findings in Lamm et al. (1972) strongly suggest. Indeed, each effect may have its own separate and distinct causes which have nothing to do with value-adherence. If this is correct and if similar doubt can be raised in respect to the self-ideal discrepancy-that the latter is not a manifestation of value-adherence processes and/or is causally unrelated to shifts in choice-the remaining support for interpersonal comparison explanations is severely undermined. Our paper contains two studies dealing with these issues. The first concerns the self-other discrepancy and the second, the self-ideal discrepancy.

\section{EXPERIMENT I}

The finding that an individual's own choice tends to be more extreme than that which he predicts for others is also consistent with at least one reasonably well established principle of social judgment, to wit: the more certain, confident, or intensely held the judgment, the more extreme its expression, say, on scales commonly used in attitude measurement (e.g., Suchman, 1950). The same type of finding has been obtained in research on the choice-shift, although little has been made of it. Thus, Clausen (1965) observed a positive correlation between extremeness of choice and the individual's confidence in the choice. Similar findings were reported by Burnstein and Katz (1971). In addition, it is known that people who have made an extreme choice appear more influential and thus probably more confident to others (e.g., Burnstein, 1969; Marquis, 1962). Finally, Stroebe and Fraser (1971) have demonstrated that confidence in one's choice and extremity of the choice are directly related for items which shift toward risk as well as those which shift toward caution.

It may well be the case, therefore, that an individual selects a more risky course (on items shifting toward risk) or a more cautious one (on items 
shifting toward caution) than that which he predicts others will choose because he is more confident or certain about his own preference than about the choice of others and not because he wishes to outshine others in adhering to cherished social values.

\section{Method}

Subjects and procedure. Forty-eight female undergraduates at the University of Provence (Aix-en-Provence) participated as part of a course requirement. They were given a booklet labeled "Opinion Questionnaire" which contained five decision items which are standard in this arca: number 2 and 8 from Stoner (1968) and number 5, 8, and 11 from the Choice Dilemma Questionnaire (CDQ) of Kogan and Wallach (1964), very slightly modified for French subjects. On each item the subject first indicated her own choice of a "risk-level" according to the usual format (see Pruitt, 1971a), that is, the minimum probability of success she would recommend in order to pursue a relatively attractive but uncertain course of action. She then indicated what in her opinion the majority of other students in psychology at the University of Provence would choose. Next, the subject indicated how confident and certain she was about her own choice and, finally, how confident and certain she was about the choice predicted for others. The latter judgments were made on a six-point scale ranging from "completely confident and ccrtain" (scale value -1 ) to "completely unconfident and uncertain" (scale value $=6$ ).

\section{Results}

Mean own and others' choices as well as mean confidence ratings on items known to shift toward risk or caution are presented in Table 1. As in past studies, a subject's own choice tends to be more extreme than the choice he attributes to others. Furthermore, as expected, she is considerably more confident and certain about the former than the latter. Out of the 240 choices made by our subjects, 192 (80\%) were ones in which confidence in one's own choice was greater than confidence in the

TABLE 1

Mran Own Cholce, Mran Choice Attributed to Others, and Mean Confidence on Risky and Cautrous Items

\begin{tabular}{llllllll}
\hline & \multicolumn{2}{c}{ Choice of risk level } & & \multicolumn{3}{c}{ Confidence in choice } \\
\cline { 2 - 3 } \cline { 6 - 7 } Item lype & Own & Others & Difference & Own & Others & Difference \\
\hline Risky & $4.64^{a}$ & 5.56 & $.92^{*}$ & $2.32^{b}$ & 3.71 & $1.39^{* *}$ \\
Cautious & $\mathbf{6 . 2 1}$ & 5.38 & $.83^{*}$ & 2.24 & 3.43 & $1.19^{* *}$ \\
Difference & $\mathbf{1 . 5 7 ^ { * * }}$ & 0.18 & & $\mathbf{0 . 0 8}$ & 0.28 & \\
\hline
\end{tabular}

\footnotetext{
${ }^{a} 1=$ choice of 1 out of $10 ; 2=$ choice of 2 out of 10 , etc.

${ }^{\circ} 1=$ completely confident and certain; $6=$ completely unconfident and uncertain.

${ }^{*} p<.05$.

${ }^{* *} p<.01$.
} 
others' choice, $36(15 \%)$ in which individuals were equally confident about own and others' choices, and only $12(5 \%)$ in which they were less confident about own than others' choices. The relationship between confidence and the minimum acceptable probability for own and other's choice averaged over items and over probability levels is shown in Fig. 1. The results for own choice are similar to those obtained by Stroebe and Fraser (1971), that is, individuals are more confident about their own extreme choices than about moderate choices, both on items known to shift toward risk and on those known to shift toward caution. In addition they were generally less certain about the choice predicted for others regardless of its extremity. For purposes of analysis the subjects' mean confidence rating $(\bar{X}=1.73)$ for own extreme choices (those falling between either " 1 out of 10 " and " 3 out of 10 " or between " 8 out of 10 " and " 10 out of 10 ") was compared with their mean confidence rating $(\bar{X}=3.55)$ for own moderate choices (those falling between " 4 out of 10 " and " 7 out of 10 "). A $t$-test for correlated means indicates the difference in confidence is significant at the .01 level. A similar comparison between confidence ratings of extreme and moderate choices attributed to others did not approach traditional levels of statistical significance.

\section{EXPERIMEN'T II}

The discrepancy between what a person chooses and what he admires seems a straightforward indication of value adherence (and, thus, the potential for comparison processes inducing a shift in choice). First, an

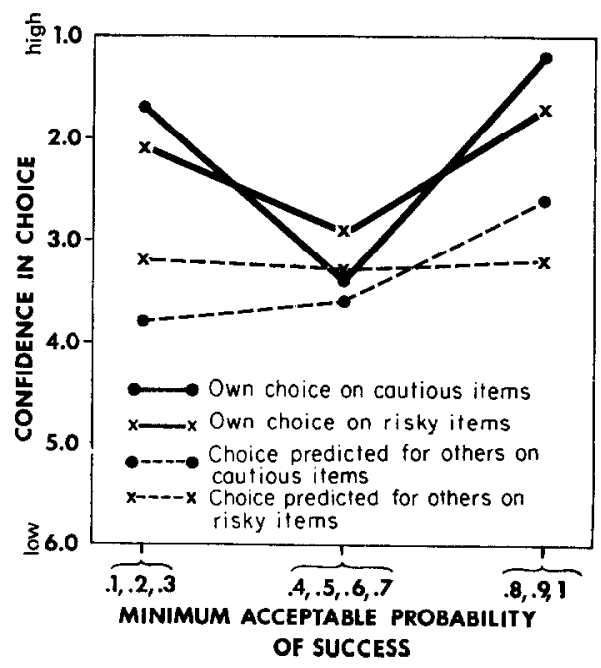

FIG. 1. Confidence in choice as a function of the probability level chosen. 
individual's own choice tends to be less extreme than the admired choice. Thus, the discrepancy cannot be explained, as in our first experiment, by hypothesizing relatively greater certainty about the former. ${ }^{2}$ Second, asking the person what he admires appears to have greater face-validity, to be a more direct guide to what is socially valued than asking him what he believes others would choose.

The straightforwardness, however, does not hold up under closer inspection of the experimental results already available. If an extreme choice reflects adherence to a cherished social value, then the person who makes such a choice should be seen as generally (perhaps even morally) good, attractive, etc., while the relatively moderate individual should be judged as generally bad, repugnant, etc. Thus, for instance, a semantic-differential analysis of the ratings of extreme and moderate individuals should find at least as much (if not more) of the variance explained in terms of the evaluative factor as is explained in terms of potency and activity. The little data available present a different picture. Madaras and Bem (1968), though they argue for interpersonal comparison theories, present results in which observers make rather small distinctions between high and low risk-taking individuals in terms of the evaluative dimension (e.g., good-bad), but marked distinctions in terms of potency (e.g., weak-strong) or activity (e.g., active-passive). Similarly, Lamm, Trommsdorff, and Rost-Schaude (1972) found that shifts in choice toward the extreme (risk) is directly related to judgments on activity and potency dimensions, but not to judgments on the evaluative dimension. This suggests that observers may infer something other than valueadherence from extreme choices.

Let us now examine these findings in the light of the persuasivearguments formulation. Consider the set of CDQ items standard in this area. ${ }^{3}$ This task has a subject read a description of a hypothetical situation

\footnotetext{
${ }^{2}$ Parenthetically, however, it does not seem out of the question that individuals may, in fact, be more certain about the action they admire than about what they would actually do in a specific instance. The latter appears to involve a larger number of contingencies-making for greater uncertainty - than the former. After all, it is not so uncommon to hear someone state he knows what he would like to do, but is not sure he will really do it in the particular circumstances. Were this the case, the same extremity-certainty relationship could account for the self-ideal discrepancy as well as the self-other discrepancy.

${ }^{3}$ For those especially concerned about the generalizability of findings based on CDQ items, they should know that very similar effects have been observed by Myers and others on several decision tasks which are quite different from the CDQ task, e.g., the decisions having nothing to do with risk or minimum probabilities of success. This work is thoroughly reviewed in Myers (1973b) and his conclusions are not significantly different from our own.
} 
in which the "hero" is confronted with a choice between a certain and an uncertain course of action. According to persuasive-arguments theory, choosing a minimum acceptable probability of success for pursuing the uncertain alternative requires the individual to consider arguments for and against the different courses of action, weigh their importance, and even make some inferences based on these ideas and on his familiarity with similar situations. Hence, the individual is literally engaged in problem-solving rather than in risk-taking, and the arguments which come to mind function as part-solutions to the problem of choice rather than justification for derring-do.

Suppose items of the CDQ type are seen as problems to be solved. Then it is reasonable to conjecture that observers may evaluate another's choice largely in terms of its being well or poorly founded. In other words, since there is no objectively correct choice, the evaluation will reflect an inference about the quality of the ideas or the persuasiveness of the arguments which we-and probably observers also-know determined the choice. Thus, an extreme preference may be admired because it is a sign of confidence, which in turn implies to observers that the person has available a large number of persuasive reasons to support his preference. According to persuasive-arguments theory, because the observer is judging the choice as a well or poorly founded solution, it is not surprising that he makes at least as strong inferences about the person's creativity and rationality (e.g., see Jellison \& Riskind, 1970) as about his goodness and attractiveness.

In the present study, observers are given two cues about the thinking which has led an individual to make a specific choice-the direction of his choice and the confidence and certainty he expressed in his choice. Upon reading a particular CDQ item, the average observer is likely to think of more arguments in favor of one alternative, that is, for the uncertain alternative, on items which shift toward risk, and for the certain over the uncertain alternative on items which shift toward caution (Silverthorne, 1971; Vinokur \& Burnstein, 1974). The observer, therefore, has an idea of which alternative has the most supportive argumentation and, in this special sense, which is likely to be correct. If the person has selected the correct alternative and is certain about his choice, observers are likely to infer that he has available many good reasons for his choice. As a result, his solution to the dilemma is judged to be of high quality, as worthy of admiration (as is, of course, the person who devised the solution). On the other hand, if the person has selected the incorrect alternative and is uncertain, observers are likely to infer he has little reason for his choice, and his solution is of poor quality. These may be considered as limiting cases. Inference about the nature of the arguments 
available to the person and the quality of his solution in the two remaining instances-a correct but uncertain choice and an incorrect but certain choice-should fall somewhere between these limiting cases. The critical point to keep in mind is that persuasive-argument theory predicts similar but independent effects for the direction of choice and for confidence in the choice.

Interpersonal comparison theories suggest something different. The social value which dominates a choice supposedly is evident from the direction in which the latter shifts following interpersonal comparison. Thus on an item which shifts, say, toward risk, an extremely risky preference (or the person having this preference) is more admirable than a moderate one because the former conforms more to the cherished value. The homage should crescendo when the extremely risky individual is also highly certain and confident about his choice, this being a display of maximal adherence to the value. Consider now the soul who prefers an extremely cautious course of action on an item which shifts toward risk. According to the interpersonal comparison formulation, he should be castigated for rejecting something widely prized; and were he to indicate his rejection is firm, that he is certain and confident about his choice, the castigation should be cven greater. Thus, interpcrsonal comparison theories imply an interaction between the direction of a choicewhether it reflects conformity to or rejection of a widely held value-and certainty or confidence in the choice. That is to say, high confidence in a deviant choice, one which rejects a widely shared social value should lead to maximal disapproval, while high confidence in a conforming choice should lead to maximal approval. Such effects are standard in field and laboratory studies of conformity (e.g., Festinger, Schachter, \& Back, 1950; Schachter, 1951). Nevertheless, this is clearly contrary to the prediction made by persuasive-arguments theory which implies additive (averaging) effects for correctness and confidence (see above). Our second study attempts to detcrmine which of the two predictions is correct.

\section{Method}

Subiects. A total of 74 female students from the introductory courses in psychology at the University of Michigan participated in this experiment as part of their course requirement.

Materials, procedure, and instructions. A set of eight CDQ items were chosen to include four risky and four cautious items. The four risky items were taken from the original CDQ set (Kogan \& Wallach, 1964, Appendix E, numbers 1, 1, 6, and 7) as were two of the cautious items (numbers 2 and 3 ). The other two cautious items came from a questionnaire used by Stoner (1968, numbers 2 and 8, respectively, in his questionnaire). 
Each choice dilemuna item was accompanied by the standard instructions to choose-between odds of $1,2,3,4,5,6,7,8$, or 9 chances in 10 -the lowest odds of success acceptable in order to recommend trying the uncertain alternative; or instead to indicate that this alternative should not be attempted, no matter what the odds. In the latter case, a response was scored as 10 . In addition, at the bottom of each item the question of "How certain and confident are you of your above choice?" was provided along with an 11-point rating scale with "completely certain, confident" at one pole and "completely uncertain and unconfident" at the other pole.

The eight items were contained in a questionnaire entitled "Opinion Questionnaire" and were preceded by the standard instructions, an explanation and an example. The items in each questionnaire were said to have been answered previously by different respondents and were assembled together in the booklet for purposes of the present study. Two check marks appeared on each item: one on the odds scale and one on the confidence scale. The placement of the check marks on the scales constitutes the experimental manipulation. They were arranged in the questionnaire to provide a $2 \times 2 \times 2$ within subject orthogonal factorial design with 2 levels of risk, 2 levels of confidence and 2 levels of item type (i.e., risky vs cautious items). More specifically, for each item, the check mark on the odds scale was either placed on high risk ( 1 or 2 in 10 ) or on low risk ( 8 or 9 in 10), and the check mark on the confidence scale was either placed on high confidence (i.e., 10) or on low confidence (i.e., 4). (The complete orthogonal pattem of check marks for the risk and confidence scales appeared once in the four risky items and once in the four cautious items.) The items were assembled in the questionnaire so that each risky item was followed by a cautious item and each item with risky check mark (1,2 in 10) was followed by an item with a cautious check mark ( 8,9 in 10). Finally, the order of each specific item in the questionnaire varied so that across subjects, each item appears at the beginning, in the middle or at the end of the questionnaire as frequently as any other item.

In addition to the "Opinion Questionnaire" which included the responses of hypothetical respondents each subject received the following instructions. "This is part of a study on how people judge others when there is not a great deal of information available on which to base such judgments. Several items from a large opinion survey will be presented in the booklet entitled "Opinion Questionnaire." You will be told how people responded to a particular opinion item and how certain they were about their opinion. We ask you to read the instructions to the Opinion Questionnaire and then read each item at a time. Immediately after considering the responses of a particular individual to an item you will make several judgments about him in the following page. Do not worry about being right or wrong nor about being somewhat unsure of your judgement. Just make what you think is the most reasonable and straightforward judgment possible about the individual in the light of his responses to the item."

Following these instructions eight pages (a page per item) were provided with a set of 9-point semantic differential rating scales. The subjects were told that each CDQ-type item had been answered hy a different respondent and that they were to rate each respondent based on the choice he had made.

The semantic differential scales that appeared on the page were highly loaded on the evaluation, activity, and potency dimensions of the semantic differential space ( see Osgood, Suci, \& Tannenbaum, 1957). The evaluation scales include intelligentunintelligent, attractive-repelling, and admirable-not admirable. The activity scales include active-passive, hot-cold, and fast-slow. The potency scales include strong- 
weak, severe-lenient, and hard-soft. The scales from the different dimensions were alternated as were the direction of the positive and negative poles.

Two additional scales were included to assess inferences the subject might make about the reasoning which lay behind a choice. On the first subjects were merely asked to rate the person for his "sincerity" ( sincere-insincere) in the semantic differential format. Then at the bottom of the page the subject was asked to "Suppose the respondent had to support his choice in an informal debate. How persuasive do you think his arguments would be?" A 9-point scale was provided with "very persuasive arguments" at one pole and "very unpersuasive arguments" at the other pole. These measures would give a rough indication of how well-founded the choice was perceived to be by observers.

\section{Results}

A subject's scores on scales belonging to the same semantic dimension were averaged. Along with our two measures of the "well-foundedness" of the choice, this gave 5 dependent variables (evaluation, activity, potency, sincerity, and persuasiveness) with the score of each varying from 1 (low) to 9 (high). A $2 \times 2 \times 2 \times 5$ analysis of variance with repeated measures on all factors was performed. The mean scores are shown in Table 2. The largest main effect is associated with the confidence factor $[(F(1,73)=81.832, p<.001]$, demonstrating that reliably higher evaluations are given if the respondent is certain and confident than if he is uncertain and unconfident, regardless of the direction of the choice. The next strongest effect is the interaction between item type and direction of choice $[F(1,73)=46.064, p<.001]$ indicating that risky preferences on items known to shift toward risky and cautious preferences on items known to shift toward caution are rated more highly than their respective opposites. An examination of the mean ratings on risky items

TABLE 2

Mean Ratings by Observers of Respondents Who Have High or Low Confidence in Their Extremely Risky or Cautious Choice on Risky and Catutious Itrams

\begin{tabular}{|c|c|c|c|c|c|c|c|c|}
\hline \multirow[b]{3}{*}{ Confidence $^{a}$} & \multicolumn{4}{|c|}{ Risky items } & \multicolumn{4}{|c|}{ Cautious items } \\
\hline & \multicolumn{2}{|c|}{ Risky choice } & \multicolumn{2}{|c|}{ Cautious choice } & \multicolumn{2}{|c|}{ Risky choice } & \multicolumn{2}{|c|}{ Cautious choice } \\
\hline & High & Low & High & Low & High & Low & High & Low \\
\hline Evaluation & 6.27 & 5.72 & 5.12 & 4.83 & 4.67 & 4.39 & 6.10 & 5.29 \\
\hline Activity & 6.61 & 5.86 & 4.53 & 4.20 & 5.97 & 5.38 & 5.23 & 4.75 \\
\hline Potency & 6.11 & 5.17 & 5.38 & 4.65 & 5.98 & 5.49 & 5.23 & 4.78 \\
\hline Persuasiveness & 6.80 & 4.45 & 6.03 & 3.74 & 5.50 & 3.39 & 7.00 & 4.12 \\
\hline Sincerity & 6.59 & 5.32 & 6.53 & 5.29 & 5.89 & 4.73 & 6.92 & 5.99 \\
\hline
\end{tabular}

$a$ Note: $1=$ low $; 9=$ high. 
reveals no case in which the ordering predicted by persuasive argument theory is violated, that is, the highly certain and risky respondent is viewed as most admirable, active, persuasive, and sincere while the cautious and uncertain respondent is seen as least admirable, active, etc., with risky but uncertain and cautious but certain respondents receiving intermediate ratings. On cautious items the predicted ordering is obtained for evaluation, persuasiveness, and sincerity, but not for activity or potency, leading to a significant second-order interaction-item type by rating dimensions by direction of choice $[F(4,292)=7.123, p<.001]$. The pattern of mean ratings for activity and potency on cautious items, however, are equally inconsistent with the order predicted by interpersonal comparison theories and suggest some stereotype about respondents who take long shots even when the correct or valued choice demands conservatism.

Separate analyses of variance were preformed for each semantic differential dimension as well as on the two indices of the "well-foundedness" of the choice. On evaluative ratings (e.g., good-bad) reliable effects are found for confidence $[F(1,737)=14.362, p<.001]$ and for the interaction between item type and direction of choice $[F(1,733)=$ $54.095, p<.001]$, indicating that high confidence choices were rated more positively than low confidence ones, as were risky choices (compared to cautious choices) on risky items and cautious choices (compared to risky choices) on cautious items. Analysis of ratings of activity (e.g., fast-slow) demonstrate reliable effects for direction of choice $[F(1,73)=$ $49.417, p<.001]$, confidence $[F(1,73)=21.877, p<.001]$, and the interaction between item type and direction of choice $[F(1,73)=30.573$, $p<.001]$. A similar pattern is obtained on ratings of potency, that is, highly reliable effects for direction of choice $[F(1,73)=41.822, p<$ $.001]$, confidence $[F(1,73)=43.970, p<.001]$, and the item type by direction of choice interaction $[F(1,73)=17.469, p<.001]$. Thus ratings of activity and potency increased as both the riskiness and the confidence of the choices increased. Moreover, while risky choices were considered more "active" and more "potent" than cautious ones on items known to shift toward risk, comparable effects were not found for cautious choices (compared to risky ones) on items known to shift toward caution.

Note that the results on evaluative rating are fully consistent with the persuasive-arguments formulation and not with theories of interpersonal comparison, that is, confidence and direction of choice have additive (averaging) effects. Similarly, ratings of activity and potency fit the former but not the latter set of theories. The main effect for direction of choice-that extremely risky choices lead to judgements of greater activity and potency regardless of item type-are predicted neither by 
persuasive argumentation nor by interpersonal comparison. Indeed it is irrelevant to these two explanations of the choice-shift. What is most important is that confidence and correctness (direction of choice) have similar and independent effects, a finding which is contrary to interpersonal comparison theories but totally consistent with persuasive argumentation.

The same is true for results from our analysis of judgements of persuasiveness and sincerity, where again we obtain significant effects for confidence (persuasivencss: $F(1,73)=132.083, p<.001$; sincerity: $F(1,73)=25.808, p<.001)$ and for the interaction between direction of choice and item type (persuasiveness: $F(1,73)=24.875, p<.001$; sincerity: $F(1,73)=11.979, p<.001)$. In other words, confident choices were perceived as more persuasive and more sincere than unconfident ones as were risky choices (compared to cautious ones) on risky items and cautious choices (compared to risky ones) on cautious items.

\section{DISCUSSION}

Our evidence strongly suggests that while discrepancies involving own, attributed, and admired choices may be reliable events, they have little to do with a desirc to outdo others in valuc adherence, as assumed by theories of interpersonal comparison.

The first study simply demonstrated that a person tends to be more extreme in his own choice than in the choice he attributes to most others because he is more confident and certain about the former than the latter. The discrepancy, therefore, probably is caused by differential certainty rather than a desire to display adherence. This finding coupled with those in Lamm et al. (1972), where no relationship was observed between such discrepancies and actual shifts makes the interpersonal comparison interpretation of the difference between own and attributed choice rather tenuous.

The second study examined the interpersonal comparison explanation of the finding that extreme choices (in the appropriate direction) are admired because they exemplify devotion to some widely held social ideal. Or put another way, moderate choices are frowned upon and extreme choices in the disvalued direction are condemned because they exemplify rejection of the value. Given such a hypothesis, it would seem to follow that an expression of great certainty and confidence in the choice should magnify admiration, when the choice is in the valued direction, or condemnation, when the choice is in the disvalued direction. Persuasive-arguments, on the other hand, assumes that an observer in large part judges a choice in terms of how correct or well-founded it is. 
In past research this judgement was made on the basis of a single cue, the direction of choice. Since the observer knows to some degree which is the correct course of action, it is not surprising that he applauds respondents with relatively strong preferences for this alternative. In the present study he is given a second cue to the quality of the reasoning underlying a choice: the respondent's certainty and confidence. This should influence his evaluation of the choice-but in a fashion different from that predicted by interpersonal comparison. That is to say, he should have more respect for preferenes about which respondents arc confident and certain than those about which they are unconfident and uncertain, independent of whether the preference is in the so-called valued or disvalued direction.

Observers' ratings on three semantic differential dimensions give fairly strong support to the persuasive-arguments formulation and not to interpersonal comparison. Moreover, the two relatively direct, albeit crude, indices of the quality of thought behind a choice-the respondent's sincerity and potential persuasiveness-seems to demonstrate nicely that an observer is evaluating respondents in terms of their problem-solving and not in terms of value adherence.

These findings, along with those mentioned earlier demonstrating that knowledge of others' choice is neither a necessary nor sufficient condition for shifts in choice, suggest that interpersonal comparison theories do not provide a tenable explanation of this phenomenon.

\section{REFERENCES}

Brows, R. Social psychology. New York: Free Press of Glencoe, 1965.

Bunnstein, E. An analysis of group decisions involving risk ("The risky shift"). Human Relations, 1969, 22, 381-395.

Burnsteis, E., \& KATz, S. Individual commitment to risky and conservative choices as a determinant of shifts in group decisions. Joumal of Personality, 1971, 39, $564-580$.

Bunnstein, E., \& Vinokur, A. Testing two classes of thcorics about group induced shifts in individual choice. Journal of Experimental Social Psychology, 1973, 9, 123-137.

Burnstein, E., Vinokur, A., \& Trope, Y. Interpersonal comparison versus persuasive argumentation: A more direct test of alternative explanations for group induced shifts in individual choice. Journal of Experimental Social Psychology, 1973, 9, 236-245.

CARtwrigirT, D. Risk taking by individuals and groups; an assessment of research employing choice dilemmas. Journal of Personality and Social Psychology, 1971, $20,361-378$.

Clank, R. D., Crockert, W. H., \& Ancien, R. L. Risk as value hypothesis: The relationship between perception of self, others and the risky shift. Journal of Personality and Social Psychology, 1971, 20, 425-429. 
Clark, R. D., \& Wirlems, E. P. Where is the risky shift. Journal of Personality and Social Psychology, 1969, 13, 215-221.

Clausen, G. S. T. Risk taking in small groups. Unpublished doctoral dissertation, University of Michigan, 1965.

Deutscr, M., \& Gerard, H. G. A study of informational social influences upon individual judgement. The Journal of Abnormal and Social Psychology, 1955, 51, 629-636.

Festinger, L., Schachter, S., \& Back, K. Social pressures in informal groups. New York: Harper, 1950.

Jellison, J. M., \& Riskind, J. A social comparison of abilities interpretation of risk taking behavior. Journal of Personality and Social Psychology, 1970, 15, 375390.

Kogav, N., \& Wallach, M. A. Risk taking: A study in cognition and personality. New York: IIolt, Rinehart and Winston, 1964.

Lamm, H., Schaude, E., \& Trommsdorff, G. Risky shift as a function of group members' value of risk and need for approval. Journal of Personality and Social Psychology, 1971, 20, 430-4.35.

Lamm, H., Trommsdorff, G., \& Rost-Schaude, E. Self-image, perception of peers' risk acceptance and risky shift. European Journal of Social Psychology, 1972, $2,255-272$.

Levinger, G., \& Schneider, D. J. A test of the risk is a value hypothesis. Journal of Personality and Social Psychology, 1969, 11, 165-169.

Madaras, G. R., \& BEM, D. J. Risk and conservatism in group decision making. Journal of Experimental Social Psychology, 1968, 4, 350-365.

McCauley, C., Kogan, N., \& Teger, A. Order effects in answering risk dilemmas for self and others. Journal of Personality and Social Psychology, 1971, 20, 423424.

MArquis, D. G. Individual responsibility and group decisions involving risk. Industrial Management Review, 1962, 3, 8-23.

MYERs, D. G. Social comparison processes in choice dilemma responding. Unpublished manuscript, Hope College, 1973. (a)

Myers, D. G. The polarizing effects of group discussion. Unpublished manuscript, Hope College, 1973. (b)

Moscovicr, S., \& LecuYer, R. Studies in group decision I: Social space, patterns of communication and group consensus. European Journal of Social Psychology, $1972,2,221-244$.

Osgood, C. E., Suci, G. J., \& Tannenbaum, P. H. The measurement of meaning. Urbana: University of Illinois Press, 1957.

Pruitr, D. G. Choice shifts in group discussion: An introductory review. Journal of Personality and Social Psychology, 1971, 20, 339-360. (a)

Pruitr, D. G. Conclusions: Toward an understanding of choice shifts in group discussion. Journal of Personality and Social Psychology, 1971, 20, 495-510. (b)

Schachter, S. Deviation, rejection, and communication. Journal of Abnormal and Social Psychology, 1951, 46, 190-207.

SмITH, M. B. Is experimental social psychology advancing? Journal of Experimental Social Psychology, 1972, 8, 86-96.

St. JEAN, R. Reformulation of the value hypothesis in group risk taking. Proceeding of the 78th Annual Convention of the American Psychological Association, 1970, 5, 339-340. 
Stroebe, W., \& Fraser, C. The relationship between riskiness and confidence in choice dilemma decisions. European Journal of Social Psychology, 1971, 1, 519526.

Stoner, J. A. F. Risky and cautious shifts in group decisions. The influence of widely held values. Journal of Experimental Social Psychology, 1968, 4, 442459.

Suchman, E. A. The intensity component in attitude and opinion research. In S. A. Stouffes et al., Measurement and prediction. Princeton: Princeton University Press, 1950.

Teger, A. I., \& Pruitr, D. G. Components of group risk taking. Journal of Experimental Social Psychology, 1967, 3, 189-205.

Vinokun, A. Review and theoretical analysis of the effects of group processes upon individual and group decisions involving risk. Psychological Bulletin, 1971, 76, 231-250.

Vinokur, A., Burnstein, E. The effects of partially shared persuasive arguments on group induced shifts: A group problem solving approach. Joumal of Personality and Social Psychology, 1974, 29.

Wallach, M. A., \& Kogan, N. The roles of information, discussion, and consensus in group risk taking. Journal of Experimental and Social Psychology, 1965, 1, $1-19$.

(Received July 30, 1973) 